\title{
Bringing our voices into the research world: lessons from the Kanyini Vascular Collaboration
}

\section{A group of Indigenous Research Fellows describe the lessons learnt from their involvement in Indigenous health research}

e are a group of Indigenous Research Fellows (IRFs) involved in the Kanyini Qualitative Study (KQS), examining barriers and enablers to chronic disease care for Indigenous Australians. The KQS forms part of the Kanyini Vascular Collaboration (KVC), a health services research program established to reduce the burden and suffering of chronic disease (http:// www.kvc.org.au).

The KQS was developed to explore five key issues:

- What frames people's decisions to access care?

- What does it mean to be looked after properly?

- What are participants' experiences of care?

- What are the principal barriers and enablers to care?

- How can these findings be used to build better systems?

The research team, comprising Indigenous and non-

Indigenous researchers, was located across four geographically diverse Aboriginal medical service sites, supported by senior researchers at the Baker IDI Heart and Diabetes Institute in Alice Springs and the George Institute for Global Health in Sydney. The KQS methodology and design included a strong commitment to building research capacity among Indigenous people by engaging us (the IRFs) as key researchers, by providing us with training, and by including us at all stages as essential members of the team.

As IRFs who were largely new to research when we began this process 4 years ago, we reflect here on what we have learnt through participation, and hope this may help other researchers build better ways of engaging Indigenous people within the research process.

\section{Including Indigenous researchers}

Research teams investigating Indigenous experience of health and health services need to include Indigenous researchers. From the outset, we were actively involved in the KQS at local sites, identifying participants, brokering participation and informed consent, conducting interviews, coding data, guiding culturally sensitive data analysis to ensure appropriate interpretation, and providing adequate feedback to our local communities and health services.

Collectively, we joined the collaboration because: "We found the opportunity too valuable to pass up", "We all have immediate and extended family whose lives are affected by cardiovascular disease, chronic kidney disease and diabetes mellitus" and "We all saw this study as giving us the opportunity to contribute to improving health for our people, to better understand chronic conditions and to find out how research can inform policy and influence systemic change".

In 2008, an experienced qualitative researcher conducted a workshop with us to facilitate the development of a draft semistructured interview guide. This guide was piloted by one of us in one community to assess its appropriateness, relevance and usefulness in a cross-cultural context. These results were fed back to the broader team and the interview guide was modified accordingly.

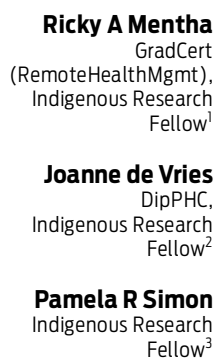

Barry N Fewquandie GradCert(PHC), Indigenous Research Fellow

John Brady BSciApp, Indigenous Research Fellow ${ }^{4}$

Suzanne Ingram BA(Comm), GradCertHealthSciences, Senior Research Fellow

1 Baker IDI Heart and Diabetes Institute, Alice Springs, NT.

2 Wuchopperen Health Service, Cairns, QLD.

3 Tharawal Aboriginal Corporation Aboriginal

Medical Service,

Sydney, NSW.

4 Inala Indigenous Health Service, Brisbane, QLD.

5 The George Institute for Global Health,
Sydney, NSW.

alex.brown@ bakeridi.edu.au doi: $10.5694 / \mathrm{mjal} 2.10640$

\section{Our reflection process}

We felt it was important to capture our experiences in interviewing Indigenous people and being responsible for communicating their stories. Reflection was embedded in the project through various forms of facilitated discussion. Fortnightly teleconferencing was the key operational forum for discussing ongoing successes and challenges, and allowed the research process to be adjusted to harmonise with critical local issues, events, staffing changes, political influences and community needs. A 1-day workshop for all KQS researchers in March 2011 allowed us to reflect together on the good and the challenging aspects of the research, what results should be shared and how they could inform the key research questions. At the 2011 annual meeting of KVC partner representatives and chief investigators, three of us were asked to reflect on the negative and positive insights gained during the project in a panel discussion.

\section{What we learnt}

\section{Our responsibilities within the research process}

We collectively felt obligated to do justice to the time given by study participants, and carrying their personal stories was a huge burden of responsibility. This is seldom discussed by other researchers, but we had a strong sense of obligation. Many of the participants we interviewed were friends or family, sometimes placing us in very difficult positions as both insiders and outsiders. This issue has been discussed by other Indigenous researchers, ${ }^{1}$ but for us it blurred the lines between what our jobs were as researchers and, more importantly, what our responsibilities were as community and family members.

At commencement of this work, we had some concerns about how research with Indigenous people has been done in the past. As with many of our community members, we were worried about research being done to Indigenous people without their consent or apparent benefit to them. We were also concerned about Indigenous people being employed as the token "blackfellas" and the potential for community experiences to be interpreted by "whitefellas" who did not really understand our lives.

As the project progressed, we remained anxious about our ability to do justice to the stories with which people had entrusted us. We feared that, as Indigenous people working for major research institutes, we might interpret people's experience as the whitefellas expected us to. 
Coming into the study, we had hopes that this research would rapidly influence systemic and professional practice change but, clearly, research can take many years to translate into health care practice. ${ }^{2,3}$ In the meantime, feedback sessions and discussions with stakeholders will create a dialogue about Indigenous people's perspectives on each of the five key issues of the study.

\section{Challenges in the interview and coding process}

We interviewed Indigenous community participants and personnel employed in both government-run and community-controlled health services delivering chronic disease care. Participants described what they thought to be proper and improper health care interactions and reflected on past negative and positive experiences.

We were able to create rapport and understanding with community participants, encouraging them to express their thoughts openly. Our role was essential to improving the connection between research and community. However, the interview process was not without challenges. Conducting face-to-face interviews was both a privilege and a burden. On the one hand, we were able to engage people to open up and divulge personal perspectives and experiences. On the other hand, we did not realise how challenging it could be for people to discuss their views on health care behaviour and the quality of the care they received.

We wanted to ensure all interview participants could talk honestly about their experiences in a safe space that did not identify them to their primary health care services. However, a number of pressures, some quite intangible, made such honest reflection difficult. Interviewing is a highly skilled activity, and interviewers need training and practice to do it well. From interview transcripts, we realised that a lack of interviewing experience had sometimes interfered with the participants expressing what they had to say, such as when the interviewer interrupted a participant's response. Some interview participants struggled to articulate their story in the time allowed. Indigenous people like to have time to reflect and discuss with other family members what they might want to say. Further, Indigenous people are often not used to seeing a service as a system, and critiquing it as such, and, for some people, criticism can seem rude.

We were integrally involved in developing a coding system for organising the interview data. The coding took 15 months. Although this seems a long time, the collaborative aspect of the study required ongoing discussions among the KQS team. We felt a burden of responsibility towards the coding process, as it was here that our responsibility for holding people's stories accurately was most at risk.

\section{Reflecting on the impact of chronic diseases}

This research has taken us on a journey of understanding the personal, financial, health and emotional costs and impacts for our people living with chronic diseases. We began to understand that the ability of Indigenous people to navigate care pathways is limited by language, different world views, social position and understanding of the severity of degenerative complications relating to chronic diseases.

These insights raised awareness of our own vulnerability. During the course of the KQS, one of us had an acute myocardial infarction. This event sent waves of concern through the other IRFs and caused us to reflect on our own vulnerability and risk of developing chronic conditions. We, as Indigenous people, understand that intergenerational rapid lifestyle and social change has had significant detrimental impacts that contribute to poor health.

\section{Managing competing workloads}

While conducting the research, most of us were working in dual roles in our Aboriginal medical services. This was a very "tough gig", trying to meet multiple and sometimes conflicting expectations. Flexibility and supportive communication strategies were essential and were able to be negotiated between collaborating researchers and health service partners. This supported effective time management and identified strategies to help us handle our workload.

engage people

to open up and

divulge personal

perspectives

and experiences

\section{Training and professional development}

Central to our engagement was a structured training program, involving learning about qualitative methods, interview techniques, coding practice, data analysis and presentation of findings. We greatly appreciated the training and professional development opportunities arising throughout the KQS and see these as essential to engaging Indigenous people more centrally in research opportunities.

\section{Conclusion}

While broad guidance for conducting research with Indigenous people exists, ${ }^{4,5}$ little research has outlined the more personal impacts of being an Indigenous researcher in a large research collaboration. For us, interviewing the study participants enabled significant insight into negative and positive experiences expressed by health practitioners and Indigenous community participants alike. This journey also put us at the table with chronic disease researchers, allowing our perspectives, insights and learning to be heard.

While we maintain a healthy concern about how research is done in Indigenous communities, we all now feel we are part of a research team focused on benefits for our people. Despite the difficulties, we felt that our communities and our employers expected us to accurately represent the stories people entrusted us with.

This journey has left us with some unanswered questions about the implementation of our findings. Will the research team be able to ensure that the findings make the health services more responsive to Indigenous people's needs? Will this research influence any systemic and professional practice change? How do we advocate for this in the political arena? These are still uncertainties for us, but we know that we are part of a team that will keep trying.
Acknowledgements: We thank the rest of the KQS team: chief investigators Alex Brown and Alan Cass, and senior researchers Bernadette Rickards, Hueiming Lui, David Peiris and Samantha Togni. The team has been generously supported by Jeannie Devitt and Valmai McDonald. This work was funded by the National Health and Medical Research Council (402797).

Competing interests: No relevant disclosures.

Provenance: Not commissioned; externally peer reviewed.

1 Smith LT. Decolonizing methodologies: research and indigenous peoples. Dunedin: University of Otago Press, 1999.

2 El-Jardali F, Lavis JN, Ataya N, Jamal D. Use of health systems and policy research evidence in the health policymaking in eastern Mediterranean countries: views and practices of researchers. Implement Sci $2012 ; 7: 2$. doi: 10.1186/1748-5908-7-2.

3 Straus SE, Brouwers M, Johnson D, et al. Core competencies in the science and practice of knowledge translation: description of a Canadian strategic training initiative. Implement Sci 2011; 6: 127. doi: 10.1186/1748-5908-6-127.

4 Henderson R, Simmons DS, Bourke L, Muir J. Development of guidelines for non-Indigenous people undertaking research among the Indigenous population of north-east Victoria. Med J Aust 2002; 176: 482-485.

5 Aboriginal Health \& Medical Research Council of New South Wales Ethics Committee. AH\&MRC guidelines for research into Aboriginal health: key principles. Sydney: AH\&MRC, 2009. 